\title{
FAKTOR-FAKTOR YANG MEMENGARUHI KEPUASAN KERJA KARYAWAN KLINIK KESEHATAN DI KOTA BEKASI
}

\author{
Amanda Setiorini ${ }^{1)}$ \\ 1) Dosen Program Studi Manajemen FE UNKRIS \\ Email: amanda.setiorini@unkris.ac.id \\ Wiwik Rachmarwi ${ }^{2)}$ \\ 2) Dosen Program Studi Manajemen FE UNKRIS \\ Alamat: Kampus UNKRIS, Jatiwaringin Jakarta Timur \\ Email: wiwikrachmarwi@unkris.ac.id
}

\begin{abstract}
This study aims to find out whether factors such as compensation, job certainty, career path, communication, relationships with superiors, and work-life balance affect job satisfaction in three health clinics. In this research is descriptive quantitative. The results show that compensation, job certainty, communication, and work-life balance affect job satisfaction. Data processing is performed using multiple regression methods
\end{abstract}

\section{Keywords: Compensation, job certainty, career path, communication, relationships with} superiors, work-life balance, job satisfaction

\section{PENDAHULUAN}

Bekerja pada klinik kesehatan memiliki tantangan sendiri. Karyawan di klinik kesehatan bekerja menghadapi orang-orang yang membutuhkan bantuan lebih besar daripada orang-orang yang sehat. Karena itu, baik tenaga kesehatan maupun staf di klik kesehatan perlu memiliki kondisi fisik dan mental yang baik dalam pekerjaannya setiap hari. Agar karyawan memiliki kondisi mental yang prima, salah satu yang perlu diperhatikan oleh manajemen adalah kepuasan kerja. Berbagai penelitian yang telah dilakukan tentang kepuasan kerja menyimpulkan bahwa kepuasan kerja karyawan berdampak positif bagi organisasi bisnis (Setiorini, 2016). Robbins (2006) menyebutkan bahwa karyawan yang puas terhadap pekerjaannya akan lebih produktif, dan hal ini telah menjadi prinsip dasar bagi manajemen selama bertahun-tahun. Sebaliknya, karyawan yang merasa tidak puas dengan pekerjaannya, justru akan menjadi beban bagi organisasi.

Menurut Robbins (2006) kepuasan kerja berdampak pada produktivitas, keabsenan, pengunduran diri, dan kepuasan pelanggan. Bagi karyawan yang berada di garis depan dan rutin berhubungan dengan pelanggan, kepuasan kerja mereka dapat meningkatkan kepuasan dan kesetiaan pelanggan. Karena karyawan yang puas berkemungkinan Iebih besar untuk menampilkan sikap ramah, ceria, dan responsif-hal-hal ini yang dihargai oleh pelanggan (Setiorini, 2016).

Hal ini menjadi penting bagi klinik kesehatan karena seluruh karyawannya, baik tenaga kesehatan maupun staf, setiap harinya berhadapan langsung dengan pasien. Apalagi, yang dihadapi adalah pasien-pasien yang sedang mengalami gangguan kesehatan, sehingga membutuhkan lebih banyak perhatian dan bantuan daripada pasien yang sehat. Penelitian ini akan menguji apakah faktor-faktor seperti kompensasi, kepastian kerja, jalur karier, komunikasi, hubungan dengan atasan, dan work-life balance berpengaruh terhadap kepuasan kerja tenaga kesehatan dan staf di ketiga klinik kesehatan tersebut. 


\section{LANDASAN TEORI}

\section{Kepuasan Kerja}

Robbins, (2006), kepuasan kerja didefinisikan sebagai sikap umum individu terhadap pekerjaannya, yang tercermin dalam sikap individu tersebut. Selain dari Robbins, beberapa definisi dari kepuasan kerja adalah ungkapan kepuasan karyawan tentang bagaimana pekerjaan mereka dapat memberikan manfaat bagi organisasi, yang berarti bahwa apa yang diperoleh dalam bekerja sudah memenuhi apa yang dianggap penting (Luthans dalam Almigo, 2004); keadaan emosional yang positif sebagai hasil dari evaluasi pengalaman kerja seseorang (Mathis dan Jackson, 2006); dan perasaan serta sikap positif dan negatif yang dirasakan karyawan terhadap pekerjaannya (Schultz dan Schultz, 2006).

Kepuasan kerja timbul sebagai respons afektif atau emosional terhadap berbagai aspek pekerjaan, baik dari interaksi dengan pekerjaan maupun dengan orang lain yang terlibat dalam pekerjaan tersebut di dalam maupun di luar organisasi. Pekerjaan membutuhkan interaksi dengan rekan kerja dan atasan, meliputi kemampuan untuk mengikuti aturan dan kebijakan perusahaan, memenuhi standar kinerja tertentu, kemampuan untuk hidup dalam kondisi pekerjaan yang kurang ideal, dan lain-lain (Robbins dan Judge, 2013). Jika seseorang tidak mendapatkan kepuasan dalam pekerjaannya, maka akan mendorong timbulnya stres kerja.

Berdasarkan teori Mello (2006), kepuasan kerja dipengaruhi oleh faktor-faktor yaitu komunikasi dengan manajemen, work-life balance, hubungan dengan atasan, kesempatan dan jalur karier, kepastian kerja, manfaat, dan kompensasi. Dari konsep ini, dilakukan modifikasi untuk membuat tema yang lebih umum, yaitu kompensasi, kepastian kerja, jalur karier, komunikasi, hubungan dengan atasan, dan work-life balance.

\section{Kompensasi}

Menurut (Dessler, 2017), kompensasi karyawan adalah semua bentuk pembayaran atau hadiah kepada karyawan yang timbul dari pekerjaan mereka. Kompensasi dapat berbentuk langsung maupun tidak langsung. Pembayaran finansial langsung adalah pembayaran dalam bentuk komisi upah dan bonus, sementara yang tidak langsung berbentuk manfaat finansial seperti asuransi. Dengan demikian, benefit juga termasuk dalam kompensasi. Kompensasi menjadi faktor yang penting karena diperlukan setiap pekerja untuk memenuhi kebutuhan hidupnya. Merujuk pada teori motivasi dari Maslow, manusia memiliki tingkatan kebutuhan yang akan mendorong motivasinya. Di tingkat bawah atau tingkat pertama adalah kebutuhan fisiologis, seperti makan dan minum. Untuk memenuhi kebutuhan ini, manusia harus bekerja dan mendapatkan imbalan dari pekerjaannya.

\section{Kepastian Kerja}

Kepastian kerja didefinisikan sebagai stabilitas dan keamanan posisi (pekerjaan) yang permanen (Mello, 2006). Rasa aman ini penting karena adanya pekerjaan menjamin kemampuan seseorang untuk memenuhi kebutuhan hidupnya. Dengan demikian, keamanan kerja adalah juga jaminan terpenuhinya kebutuhan hidup seseorang.

\section{Jalur Karier}

Faktor kesempatan dan jalur karier disederhanakan menjadi jalur karier. Karier (Dessler, 2017) adalah posisi pekerjaan yang dipegang seseorang selama bertahun-tahun. Karena karier merupakan bagian dalam pengembangan diri manusia di dalam pekerjaannya, maka setiap organisasi perlu melakukan manajemen dan perencanaan karier. 
Dalam manajemen karier diiperlukan pengembangan karier, yaitu serangkaian kegiatan seumur hidup yang berkontribusi pada eksplorasi, pembangunan, kesuksesan, dan pemenuhan karier seseorang (Dessler, 2017)

\section{Komunikasi}

Menurut (Robbins dan Judge, 2013), komunikasi adalah proses pertukaran dan pemahaman makna, serta menyediakan informasi yang dibutuhkan untuk membuat keputusan dengan cara menyampaikan data untuk mengidentifikasi dan mengevaluasi pilihan yang tersedia. Dalam organisasi manapun, komunikasi dapat berjalan dari bawahan kepada atasan maupun sebaliknya, juga dengan kolega atau rekan yang setara. Komunikasi juga menjadi penting dalam hubungan dengan atasan.

\section{Hubungan dengan Atasan}

Hubungan dengan atasan di Indonesia sering kali menjadi rumit karena menunjukkan ketidaksetaraan posisi diantara keduanya. Hubungan juga dipengaruhi oleh kepribadian masing-masing pihak, serta kondisi pada saat tertentu. Karenanya, hubungan yang baik dengan atasan tidak dapat dilihat dalam jangka waktu singkat.

\section{Work-life Balance}

Work-life balance dibutuhkan karena beberapa alasan (Robbins dan Judge, 2013), yaitu terciptanya organisasi global juga berarti bahwa dunia tidak pernah beristirahat, teknologi komunikasi memungkinkan orang bekerja di mana saja-yang mengaburkan batas antara rumah dengan kantor (pekerjaan), dan semakin banyak pasangan suami-istri yang sama-sama bekerja membuat pemenuhan komitmen terhadap keluarga menjadi lebih menantang. Sejumlah penelitian menyebutkan bahwa konflik antara kehidupan di kantor dan di luar kantor, khususnya antara tanggung jawab pekerjaan dengan keluarga, merupakan sumber stres yang signifikan (Robbins dan Judge, 2013). Hal ini menjadi lebih sulit ketika dalam keluarga terdapat anak kecil, orang tua, orang sakit, dan orangtua tunggal yang memerlukan perhatian lebih.

\section{METODE PENELITIAN}

Penelitian ini dilakukan di tiga klinik kesehatan di Kota Bekasi. Ketiga klinik tersebut adalah Klinik Taman Firdaus Medika di Perum Taman Firdaus Residance Blok A 6 no. 17, Cibarusah, Bekasi, Klinik Sukaraya Medika di Perum Sukaraya Indah Blok E 14 no. 4-6 , Karang Bahagia, Cikarang Utara, dan Klinik Permata Jingga Medika di Perum Pilar Imanan Residance Blok C2 no. 1, Serang Baru, Cikarang Selatan, Kota Bekasi. Hanya Klinik Taman Firdaus Medika yang memiliki fasilitas rawat inap, sementara dua lainnya merupakan klinik pratama 24 jam. Klinik pratama adalah klinik yang menyelenggarakan pelayanan medik dasar, dipimpin oleh seorang dokter atau dokter gigi dan tenaga medisnya minimal terdiri dari 2 (dua) orang dokter dan/atau dokter gigi.

Penelitian dilakukan dengan menyebarkan kuesioner ke Google Form melalui aplikasi WhatsApp. Kuesioner ini terdiri dari 5 butir pertanyaan mengenai kompensasi $\left(\mathrm{X}_{1}\right), 5$ butir pertanyaan mengenai kepastian kerja $\left(\mathrm{X}_{2}\right), 4$ butir pertanyaan mengenai jalur karier $\left(\mathrm{X}_{3}\right), 3$ butir pertanyaan mengenai komunikasi $\left(\mathrm{X}_{4}\right), 5$ butir pertanyaan mengenai hubungan dengan atasan $\left(\mathrm{X}_{5}\right), 5$ butir pertanyaan mengenai work-life balance $\left(\mathrm{X}_{6}\right)$, keenam variabel ini adalah variabel bebas, dan 4 butir pertanyaan mengenai kepuasan kerja sebagai variabel terikat $(\mathrm{Y})$. 
Jumlah karyawan adalah 60 orang, yang terdiri dari tenaga kesehatan dan staf. Dengan menggunakan tabel Isaac dan Michael, jumlah sampel yang diambil adalah 52 orang dengan taraf signifikansi 0.05. Metode analisis yang digunakan adalah metode regresi linear berganda. Hipotesis yang diuji adalah pengaruh kompensasi, kepastian kerja, jalur karier, komunikasi, hubungan dengan atasan, dan work-life balance terhadap kepuasan kerja.

\section{HASIL PENELITIAN DAN PEMBAHASAN}

\section{Hasil Penelitian}

\section{Karakteristik responden}

Data responden disajikan pada Tabel 1, menegaskan bahwa responden laki-laki merupakan 11,54\% dari total responden dan responden perempuan adalah 88,46\%, sebagian besar responden berada pada usia kurang dari 25 tahun yaitu sebanyak 86,54\%, dengan lama bekerja kurang dari satu tahun sebanyak 73,08\%, sebagian besar responden belum menikah (lajang) yaitu sebanyak 92,31\%. Sebanyak $71,15 \%$ responden berpendidikan SMA, sebagian besar responden memiliki posisi sebagai staf yaitu 51,92\%, dan sebagian besar pengeluaran per bulan responden sebesar kurang dari 5 juta yaitu $92,31 \%$.

Tabel 1 Karakteristik Responden

\begin{tabular}{cccc}
\hline Uraian & Keterangan & Jumlah & \% \\
\hline Jenis Kelamin & Pria & 6 & 11,54 \\
Usia & Wanita & 46 & 88,46 \\
& $<$ dari 25 tahun & 45 & 86,54 \\
& $25-29$ tahun & 6 & 11,54 \\
Lama Bekerja & $30-34$ tahun & 1 & 1,92 \\
& $<1$ tahun $=38$ & 38 & 73,08 \\
& 1 tahun $=6$ & 6 & 11,54 \\
& 2 tahun $=4$ & 4 & 7,69 \\
& 3 tahun $=1$ & 1 & 1,92 \\
Status & 4 tahun $=1$ & 1 & 1,92 \\
Pernikahan & 5 tahun $=0$ & 0 & 0 \\
Pendidikan & 6 tahun $=2$ & 2 & 3,85 \\
& Lajang & 48 & 92,31 \\
& Menikah & 4 & 7,69 \\
Posisi & SMA & 37 & 71,15 \\
Pekerjaan & Diploma & 10 & 19,23 \\
& Sarjana & 5 & 9,62 \\
Pengeluaran & Staf & 27 & 51,92 \\
per bulan & Perawat & 24 & 46,15 \\
& Dokter & 1 & 1,92 \\
& $<5$ juta & 48 & 92,31 \\
& Rp5 juta- Rp10 juta & 3 & 5,77 \\
& $>10$ Juta & 1 & 1,92 \\
\hline
\end{tabular}




\section{Hasil uji validitas dan uji reliabilitas}

Dari perhitungan koefisien korelasi skor tiap butir pernyataan kompensasi sebanyak 5 butir pertanyaan, kepastian kerja sebanyak 5 butir pertanyaan, jalur karier sebanyak 4 butir pertanyaan, komunilasi sebanyak 3 butir pertanyaan, hubungan dengan atasan sebanyak 5 butir pertanyaan, work-life balance sebanyak 5 butir pertanyaan, dan kepuasan kerja sebanyak 4 butir pertanyaan Dari semua butir pernyataan tersebut dinyatakan hasilnya adalah valid (r-hitung > r-tabel).

Dalam tabel 2, hasil pengujian reliabilitas diketahui bahwa semua variabel menunjukkan Cronbach's Alpha lebih besar dari 0,6 yang merupakan batas minimal koefisien reliabilitas dapat dianggap baik. Berarti semua variabel dalam penelitian ini dapat diandalkan (reliabel).

Tabel 2: Hasil Uji Reliabilitas

\begin{tabular}{lccc}
\hline \multicolumn{1}{c}{ Variabel } & $\begin{array}{c}\text { Cronbach } \\
\text { Alpha }\end{array}$ & $\begin{array}{c}\text { Nilai Kritis } \\
(\boldsymbol{\alpha}=\mathbf{0 , 0 5})\end{array}$ & Keterangan \\
\hline Kompensasi & 0,935 & 0,6 & Reliabel \\
Kepastian kerja & 0,626 & 0,6 & Reliabel \\
Jalur karier & 0,677 & 0,6 & Reliabel \\
Komunikasi & 0,657 & 0,6 & Reliabel \\
Hubungan dengan atasan & 0,734 & 0,6 & Reliabel \\
Work-Life Balance & 0,641 & 0,6 & Reliabel \\
Kepuasan kerja & 0,880 & 0,6 & Reliabel \\
\hline
\end{tabular}

Sumber: Data primer, olah data, 2020

\section{Analisis Regresi Linear Berganda}

Tabel 3. Pengaruh Faktor-faktor Kepuasan Kerja Karyawan Klinik Kesehatan

\begin{tabular}{|c|c|c|c|c|c|c|}
\hline \multirow[b]{2}{*}{ Variabel } & \multicolumn{6}{|c|}{ Parameter } \\
\hline & Mult. R & $\mathbf{R}^{2}$ & Konstanta & $\begin{array}{c}\text { Koefisien } \\
\text { Regresi }\end{array}$ & t-hitung & Sig. \\
\hline Kompensasi & \multirow{6}{*}{0.822} & \multirow{6}{*}{0.676} & \multirow{6}{*}{-22.853} & 0,281 & 3,094 & 0,003 \\
\hline Kepastian kerja & & & & 0,402 & 2,913 & 0,006 \\
\hline Jalur karier & & & & 0,190 & 1,110 & 0,273 \\
\hline Komunikasi & & & & 0,467 & 2,069 & 0,044 \\
\hline Hub. dengan atasan & & & & 0,253 & 1,582 & 0,121 \\
\hline Work-Life Balance & & & & 0,398 & 3,072 & 0,004 \\
\hline F hitung $>\mathrm{F}$ tabel $=$ & $394>3$ & & & & & 0,000 \\
\hline
\end{tabular}

Sumber: Data primer, olah data 2020

Berdasarkan tabel 4, diperoleh nilai $\mathrm{F}$ hitung sebesar 15.671, berarti kompensasi, kepastian kerja, jalur karier, komunikasi, hubungan dengan atasan, dan work-life balance berpengaruh signifikan terhadap kepuasan kerja. Nilai koefisien determinasi $\left(\mathrm{R}^{2}\right)$ adalah sebesar 0,676 atau 67,6\%, artinya kompensasi, kepastian kerja, jalur karier, komunikasi, hubungan dengan atasan, dan work-life balance memberikan kontribusi kepada kepuasan kerja karyawan klinik kesehatan adalah sebesar $67,6 \%$, sedangkan sisanya sebesar $32,4 \%$ disumbangkan oleh variabel lainnya yang tidak diteliti. 
Berdasarkan hasil perhitungan koefisien regresi secara simultan diperoleh persamaan regresi yaitu sebagai berikut;

$$
Y=-22.853+0.281 X_{1}+0,402 X_{2}+0,190 X_{3}+0.467 X_{4}+0.253 X_{5}+0.398 X_{6}
$$

Koefisien kompensasi bertanda positif sebesar 0,281, artinya setiap peningkatan kompensasi, kepuasan kerja karyawan klinik kesehatan akan meningkat dengan asumsi variabel lain tetap. Koefisien kepastian kerja bertanda positif sebesar 0,402, artinya setiap peningkatan kepastian kerja, kepuasan kerja akan meningkat dengan asumsi variabel lain tetap. Koefisien jalur bertanda positif sebesar 0,190, artinya setiap peningkatan jalur karier, kepuasan kerja akan meningkat dengan asumsi variabel lain tetap. Koefisien komunikasi bertanda positif sebesar 0,467, artinya setiap peningkatan komunikasi, kepuasan kerja akan meningkat dengan asumsi variabel lain tetap. Koefisien hubungan dengan atasan bertanda positif sebesar 0,253, artinya setiap peningkatan hubungan dengan atasan, kepuasan kerja akan meningkat dengan asumsi variabel lain tetap. Koefisien work-life balance bertanda positif sebesar 0,398, artinya setiap peningkatan work-life balance, kepuasan kerja akan meningkat dengan asumsi variabel lain, seperti; kompensasi, kepastian kerja, jalur karier, komunikasi, dan hubungan dengan atasan tetap.

\section{Pembahasan}

\section{Pengaruh Kompensasi Terhadap Kepuasan Kerja}

Kompensasi mendorong peningkatan kepuasan kerja karyawan klinik kesehatan di Kota Bekasi, hal ini dikarenakan kompensasi merupakan alasan utama seseorang dalam bekerja, terutama pada masyarakat ekonomi menengah. Kemampuan memenuhi kebutuhan hidup yang disediakan oleh kompensasi yang sesuai dari tempat kerja merupakan sumber kepuasan kerja yang signifikan. Hasil penelitian ini mendukung penelitian yang dilakukan oleh Hardiyana, Nurhadian dalam penelitian pengaruh kompensasi dan motivasi kerja terhadap kepuasan kerja serta implikasinya pada kinerja karyawan

\section{Pengaruh Kepastian Kerja Terhadap Kepuasan Kerja}

Kepastian kerja mendorong peningkatan kepuasan kerja karyawan klinik kesehatan di Kota Bekasi, hal ini dikarenakan dalam masa transisi seperti sekarang ini, memiliki pekerjaan untuk memenuhi kebutuhan hidup merupakan poin krusial. Terkait dengan faktor sebelumnya, yaitu kompensasi, kepastian memiliki pekerjaan dan kompensasi yang menyertainya merupakan alasan untuk merasa puas dengan pekerjaannya. Hasil penelitian ini mendukung penelitian yang dilakukan oleh pada penelian berjudul pengaruh kepastian tugas terhadap kepuasan kerja yang dimediasi oleh pemberdayaan psikologis: Kasus Pegawai Negeri Sipil Universitas Di Kalimantan Barat

\section{Pengaruh Jalur Karier Terhadap Kepuasan Kerja}

Jalur karier mendorong peningkatan kepuasan kerja karyawan klinik kesehatan di Kota Bekasi, hal ini dikarenakan karier merupakan bagian yang tak terpisahkan dari pekerjaan. Dengan karier yang meningkat, karyawan berharap bahwa kompensasi finansial maupun non-finansial yang didapatnya akan lebih baik. Hasil penelitian ini mendukung penelitian yang dilakukan oleh Utomo pada judul penelitan pengaruh pengembangan karir terhadap kepuasan kerja karyawan dengan motivasi kerja sebagai variabel intervening 


\section{Pengaruh Komunikasi Terhadap Kepuasan Kerja}

Komunikasi mendorong peningkatan kepuasan kerja karyawan klinik kesehatan, di Kota Bekasi, hal ini karena sebagai penyedia layanan jasa kesehatan, mampu menjalin komunikasi yang baik dengan rekan kerja dan konsumen merupakan modal dasar untuk membangun hubungan yang saling menghargai. Dengan demikian komunikasi penting agar karyawan merasa nyaman dengan lingkungan kerjanya, dan hal ini pada akhirnya akan mendorong tumbuhnya kepuasan kerja. Hasil penelitian ini mendukung penelitian yang dilakukan oleh Wirawan pada judul penelitian pengaruh komunikasi, motivasi dan lingkungan, kerja fisik terhadap kepuasan kerja Pegawai Sekretariat Daerah Kota Denpasar

\section{Pengaruh Hubungan Dengan Atasan Terhadap Kepuasan Kerja}

Hubungan dengan atasan mendorong peningkatan kepuasan kerja karyawan klinik kesehatan di Kota Bekasi, hal ini karena hubungan baik dengan atasan-yang kerap dianggap sebagai "bukan teman"—dapat membuat karyawan merasa nyaman bekerja. Ia tidak merasa diintimidasi atau direndahkan, namun dipercaya untuk mengembangkan diri secara maksimal. Hubungan baik dengan atasan merupakan bagian dari lingkungan kerja yang secara psikologis memengaruhi kepuasaan karyawan terhadap pekerjaan. Hasil penelitian ini mendukung penelitian yang dilakukan oleh Budiman pada judul penelitian pengaruh kualitas hubungan antara atasan-bawahan terhadap perilaku kerja kontra produktif

\section{Pengaruh Work-Life Balance Terhadap Kepuasan Kerja}

Work-life balance mendorong peningkatan kepuasan kerja karyawan klinik kesehatan di Kota Bekasi, hal ini karena sebagai individu, karyawan juga memiliki sisi lain yang perlu dipenuhi. Di masa pandemi seperti sekarang ini, tenaga kesehatan cenderung dibutuhkan di garis depan sehingga mungkin kehilangan waktu untuk kehidupan pribadinya. Dengan memberikan kesempatan agar karyawan dapat menjaga keseimbangan antara berbagai kebutuhannya, fasilitas kesehatan ini membuat karyawan merasa nyaman bekerja dan kemudian meningkatkan kepuasan kerja mereka. Hasil penelitian ini mendukung penelitian yang dilakukan oleh Iswardhani, Brasit, dan Mardiana dalam judul penelitan pengaruh work-life balance dan burnout terhadap kepuasan kerja karyawan

\section{KESIMPULAN DAN SARAN}

\section{Kesimpulan}

Berdasarkan hasil penelitian dan pembahasan, faktor-faktor yang mendorong peningkatan kepuasan kerja karyawan klinik kesehatan di Kota Bekasi adalah kompensasi, kepastian kerja, jalur karier, komunikasi, hubungan dengan atasan, dan work-life balance.

\section{Saran}

1. Manajemen klinik kesehatan di Kota Bekasi perlu mempertimbangkan bahwa untuk meningkatkan kepuasan kerja karyawan dibutuhkan kompensasi, kepastian kerja, jalur karier, komunikasi, hubungan dengan atasan, dan work-life balance.

2. Manajemen klinik kesehatan di Kota Bekasi perlu mempertimbangkan bahwa untuk meningkatkan kepuasan kerja karyawan agar diperhatikan, antara lain; jam kerja yang lebih pendek, tidak ada shift malam, kerja sama dalam tim, pengembangan diri, budaya, bonus tahunan, dan apresiasi non-finansial.

3. Manajemen klinik kesehatan di Kota Bekasi perlu mempertimbangkan bahwa untuk meningkatkan kepuasan kerja karyawan agar mulai membuka diri untuk memberikan 
kesempatan karyawan dalam pengembangan diri, dicari tahu bakat dan keterampilan karyawan.

4. Manajemen klinik kesehatan di Kota Bekasi perlu mempertimbangkan bahwa untuk meningkatkan kepuasan kerja karyawan agar menciptakan hubungan antara karyawan dengan atasan dapat terjalin harmonis, sehingga tercipta keharmonisan dan kelancaran dalam bekerja.

\section{DAFTAR PUSTAKA}

Almigo, N. (2004). Hubungan antara Kepuasan Kerja dengan Produktivitas Kerja Karyawan. Jurnal Psyche, 1(1), 50-60.

Dessler, G. (2017). Human Resource Management (15 ${ }^{\text {th }}$ ed.). Essex: Pearson Education, Inc.

Mathis, R. L., \& Jackson, J. J. (2006). Manajemen Sumber Daya Manusia (10 ${ }^{\text {th }}$ ed.). Salemba Empat.

Mello, J. A. (2006). Strategic human resource management ( $2^{\text {nd }}$ ed.). Mason: Thomson Corporation.

Robbins, S. P. (2006). Perilaku Organisasi (10 ${ }^{\text {th }}$ ed.). Indeks.

Robbins, S. P., \& Judge, T. A. (2013). Organizational Behavior $\left(15^{\text {th }}\right.$ ed). New Jersey: Pearson Education, Inc.

Schultz, D., \& Schultz, S. E. (2006). Psychology and Work Today (Ninth). Prentice Hall PTR.

Setiorini, A. (2016). Faktor-Faktor yang Memengaruhi Kepuasan Kerja dan Pengaruhnya terhadap Pengunduran Diri Karyawan (Studi Kasus: Feminagroup). Jurnal Manajemen Bisnis Krisnadwipayana, 4(2). 